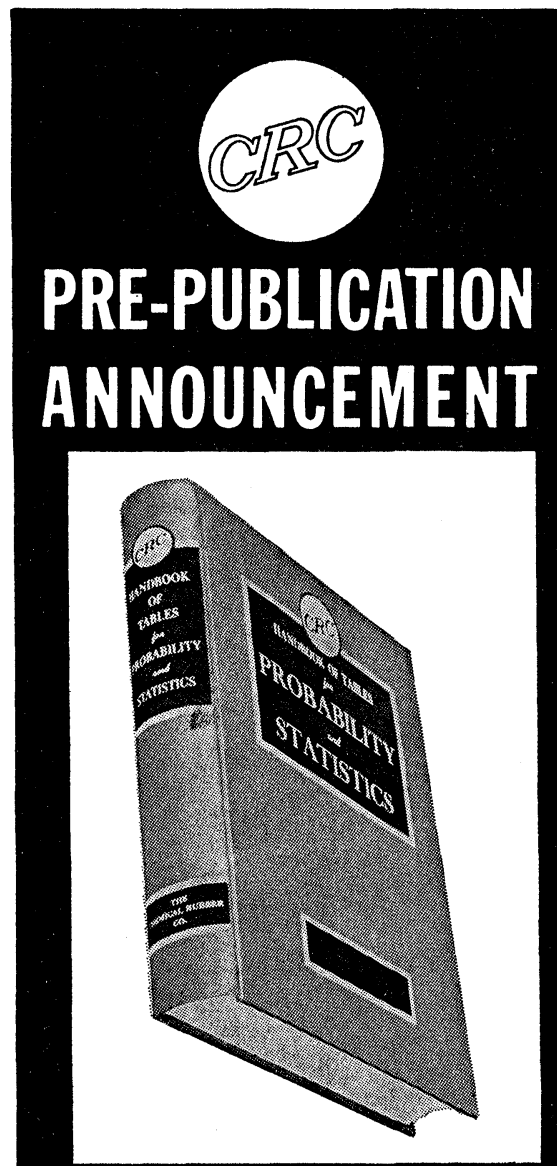

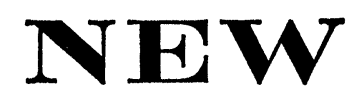

MOST COMPLETE PROBABILITY

\section{and STATISTICS HANDBOOK}

- 13 SECTIONS INCLUDE: A comprehensive discussion of probability and statistical theory (including a discussion of the General Linear Model) - Discussion and tables on: Order Statistics - Non-Parametric Statistics - Normal Distribution, Binomial, Poisson, Hypergeometric and Negative Binomial Distributions - Students t-Distribution - Chi-Square Distribution - FDistribution - Range and Studentized Range Correlation Coefficient - Quality Control ALSO: MISCELLANEOUS STATISTICAL TABLES and MISCELLANEOUS MATHEMATICAL TABLES.

- UNIQUE ARRANGEMENT OF INFORMATION includes a discussion of each table immediately preceding each table.

- Offers wide coverage of probability for statistical use and a pleasing balance of discussion and tabular data.

world-famous CRC Handbook of Chemistry and Physics

- over 500 pages and OVer 70 LARGE TABLES

- LARGE 71/2" x 101/2" PAGE SIZE

Catalog No. 5691

PRE-PUBLICATION PRICE $\$ 15.00 \mathrm{EACH}$

(Outside U.S.A. Add 50ל)

\section{ORDER TODAY AND SAVE!}

THE CIIEMTCAL TRUIBAER $C O$. 2310 SUPERIOR AVENUE - CleVElaND, OHIO 44114
THE CHEMICAL RUBBER CO.

2310 Superior Avenue

Dept. BA-3

Cleveland, Ohio 44114

PLEASE SEND UPON PUBLICATION:

Copies of CAT. NO. 5691

"CRC Handbook of Tables for Probability and Statistics" @ \$15.00 each FREE Copy of "Scientific Review" Showing the Complete line of Reference Books for Technical Personnel

Name

Firm

Address

City. State Zip

$\square$ Remittance Attached

$\square$ Purchase Order Attached 


\section{The 2uest Eo the \\ Gommitment}

The Age of Space is also the Age of Land and Sea. At Lockheed there are no environmental limits to technological exploration and progress. On land: highly advanced vehicle systems for missions of the future. In the sea: deep submersibles to probe the ocean depths, Poseidon and Polaris to keep the peace. In space: Agena, most versatile vehicle system of the age.

Engineers and scientists are invited to write Mr. K. R. Kiddoo, Professional Placement Manager, Sunnyvale, California. An Equal Opportunity Employer.

\section{LOCKHEED




\section{Journals Published by the American Mathematical Society}

\section{Soviet Mathematics-Doklady}

Soviet MATHEMATICS-DOKLADY is a translation journal containing the entire pure mathematics section of the DOKLADY AKADEMIY NAUK SSSR, the Reports of the Academy of Sciences of the USSR. The DokLADY for a year contains more than 500 articles, each about 4 pages long. Issued bimonthly in January, March, May, July, September, and November.

\section{Mathematical Reviews}

This journal is devoted to abstracts and reviews of the current mathematical literature of the world. Two volumes of MATHEMATICAL REVIEWS will be published in 1966, Volume 31, and Volume 32. Each volume will consist of 6 regular issues plus an index issue. In each regular issue the abstracts and reviews are grouped under subject headings. Publication began in 1940.

\section{Notices of the American Mathematical Society}

This journal announces the programs of the meetings of the Society. It carries the abstracts of all contributed papers presented at the meetings of the Society and publishes news items of interest to mathematical scientists.

All communications should be addressed to the Editor, P.O. Box 6248, Providence, Rhode Island 02904. News items and insertions for each issue must be in the hands of the editor on or before the deadline for the abstracts for the papers to be presented in the meetings announced in that issue. These deadlines are published regularly on the back of the title page.

\section{Mathematics of Computation}

A journal devoted to original papers in numerical analysis, the application of numerical methods and high-speed calculator devices, the computation of mathematical tables, the theory of high-speed calculating devices and other aids to computation. In addition it publishes reviews and notes in these and related fields.

Prospective publications should be addressed to the Editor, Professor Eugene Isaacson, University Computing Center, Courant Institute of Mathematical Sciences, New York University, 251 Mercer Street, New York, New York 10012. The author may suggest the name of an editor for review of his paper.

\section{Chinese Mathematics-Acta}

This is a cover-to-cover translation into English of Acta Mathematica Sinica published by Academia Sinica Peking, People's Republic of China. Acta Mathematica Sinica contains current research in all fields of pure mathematics.

Volume 1, 1962 of the translation (corresponding to Volume 10, 1960 of the original) contained three issues. Volume 2-6 (1963-1965) contain four issues each. 


\section{Journals Published by the American Mathematical Society}

\section{Bulletin of the American Mathematical Society}

This journal is the official organ of the Society. It reports official acts of the Society and the details of its meetings. It contains some of the officially invited addresses presented before the Society, reviews of advanced mathematical books, research problems and a department of research announcements.

The subscription price is $\$ 12.00$ per annual volume of six numbers.

Research Problems and Invited Addresses offered for publication should be sent to Murray Gerstenhaber, School of Mathematics, Institute for Advanced Study, Princeton, New Jersey 08540; Book Reviews to FELIX BROwDER, Department of Mathematics, University of Chicago, Chicago, Illinois 60637. Research Announcements offered for publication should be sent to some member of the Council of the Society, and communicated by him to E. H. SPANIER, Department of Mathematics, University of California, Berkeley, California 94720. All other communications to the editors should be sent to the Managing Editor, FELIX BROwDER.

The members of the Council for 1966 are: A. A. Albert, H. A. Antosiewicz, R. F. Arens, Maurice Auslander, Felix Browder, R. C. Buck, Eugenio Calabi, A. P. Calderon, Lamberto Cesari, P. J. Cohen, P. E. Conner, C. W. Curtis, J. B. Diaz, Eldon Dyer, Samuel Eilenberg, Walter Feit, Murray Gerstenhaber, J. W. Green, P. R. Halmos, O. G. Harrold, G. A. Hedlund, M. H. Heins, Henry Helson, Edwin Hewitt, Kenneth Hoffman, Eugene Isaacson, Fritz John, Mark Kac, V. L. Klee, Norman Levinson, M. M. Loève, G. W. Mackey, W. T. Martin, A. P. Mattuck, J. W. Milnor, C. B. Morrey, G. D. Mostow, Louis Nirenberg, Ivan Niven, R. S. Palais, Frank Peterson, R. S. Pierce, Everett Pitcher, Irving Reiner, Alex Rosenberg, Dana Scott, Seymour Sherman, Stephen Smale, E. H. Spanier, N. E. Steenrod, Michio Suzuki, J. D. Swift, A. E. Taylor, John Wermer, Daniel Zelinsky, Antoni Zygmund.

\section{Proceedings of the American Mathematical Society}

This journal is devoted entirely to research in pure and applied mathematics and is devoted principally to the publication of original papers of moderate length. A department called Shorter Notes was established for the purpose of publishing very short papers of an unusually elegant and polished character, for which there is normally no other outlet.

Papers in algebra and number theory should be sent to ARTHur P. Matruck, Department of Mathematics, Massachusetts Institute of Technology, Cambridge, Massachusetts or IRVING REINER, Department of Mathematics, University of Illinois, Urbana, Illinois; in probability, real variables, logic, and foundations to R. C. BUCK, Department of Mathematics, University of Wisconsin, Madison, Wisconsin 53705; in abstract analysis to either R. C. BuCK, or FRITZ JoHN, Courant Institute of Mathematical Sciences, 4 Washington Place, New York, New York 10002; in geometry and topology to ELDON DYER, Department of Mathematics, Rice University, Houston, Texas 77001; in other branches of analysis, applied mathematics, and all other fields to W. H. J. Fuchs, Department of Mathematics, University of Illinois, Urbana, Illinois or FrITz JoHN. All other communications to the editors should be addressed to the Managing Editor, R. C. Buck.

\section{Transactions of the American Mathematical Society}

This journal is devoted entirely to research in pure and applied mathematics, and includes in general longer papers than the PROCEEDINGS.

Papers in analysis and applied mathematics should be sent to LoUIS NIRENBERG, Courant Institute of Mathematical Sciences, New York University, New York, New York 10012; in topology to FRANK PETERson, Department of Mathematics, Massachusetts Institute of Technology, Cambridge, Massachusetts 02139; in algebra, number theory, and logic to DANIEL ZeLINSKy, Department of Mathematics, Northwestern University, Evanston, Illinois; in geometry and abstract analysis to R. S. PalaIs, Department of Mathematics, Brandeis University, Waltham, Massachusetts; in statistics and probability to MICHEL Lok̀ve, Department of Statistics, University of California, Berkeley, California 94720; in mathematical logic and foundations to DaNA Scotr, Department of Mathematics, Stanford University, Stanford, California 94305. All other communications to the editors should be addressed to the Managing Editor, LouIs NIRENBERG. 


\section{CONTENTS-Continued from back cover}

R. M. Solovay. New proof of a theorem of Gaifman and Hales. . . . . . . . . . . . . . . . . . . . . .

K. L. Cooke. Functional differential equations close to differ-

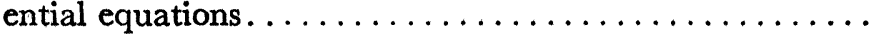

Brother B. A. deValcourt. Measures of axial symmetry for

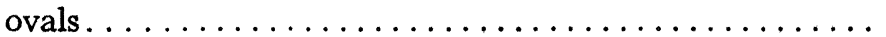

C. B. Thomas. The oriented homotopy type of 3-manifolds

C. $H$. Yang. A construction for maximal $(+1,-1)$-matrix of

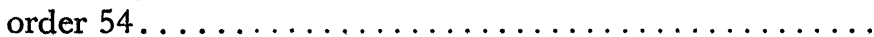

William Parry. Generators and strong generators in ergodic theory. . . . . . . . . . . . . . . . . . . . . . . 294

Gerald Freilich. Centers of curvature... . . . . . . . . . . 297

Jack Segal. Isomorphic complexes. II.... . . . . . . . 300

S. S. Shatz. Grothendieck topologies over complete local rings 303

Bui An Ton. On nonlinear elliptic boundary-value problems 307

T. S. Wu. Left almost periodicity does not imply right almost

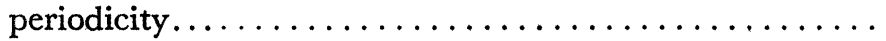

W. M. Bogdanowicz. Integral representation of multilinear continuous operators from the space of Lebesgue-Bochner summable functions into any Banach space..........

Armand Brumer. Pseudocompact algebras, profinite groups and class formations. . . . . . . . . . . . . . . . .

Phyllis Graham. Cohomology of dihedral groups of order $2 p$

A. Marden and B. Rodin. A complete extremal distance problem on open Riemann surfaces. . . . . . . . . . .

W. V. Petryshyn. On a fixed point theorem for nonlinear $\boldsymbol{P}_{-}$ compact operators in Banach space . . . . . . . . . . . . . 329

Karl Gustafson. A perturbation lemma . ............ 334

Walter Rudin. Ideals with small automorphisms . . . . . . . 339

ERRATA, Volume $71 \ldots \ldots \ldots \ldots \ldots \ldots \ldots \ldots \ldots \ldots, 342$ 


\section{GONTENTS \\ March, 1966}

\section{Survey Article}

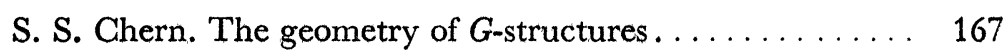

Research Problems............................... 220

The November Meeting in Iowa...................... 224

\section{Research Announcements}

William Browder. Embedding 1-connected manifolds.... . 225

W. M. Bogdanowicz. Multilinear Lebesgue-Bochner-Stieltjes integral........................... 232

L. D. Baumert. Hadamard matrices of orders 116 and 232 . 237

William Browder. Manifolds with $\pi_{1}=Z \ldots \ldots \ldots \ldots \ldots .238$

M.F. Atiyah and R. Bott. A Lefschetz fixed point formula for elliptic differential operators................... 245

M. H. Protter and H. F. Weinberger. On the spectrum of general second order operators............... 251

D. W. Anderson, E. H. Brown, Jr. and F. P. Peterson. Spin cobordism............................ 256

G. R. Sell. Almost periodic and periodic solutions of difference equations. ..........................

W. E. Franck and D. L. Hanson. Some results giving rates of convergence in the law of large numbers for weighted sums of independent random variables............... 266

P. J. Sally, Jr. Uniformly bounded representations of the universal covering group of $\mathrm{SL}(2, \boldsymbol{R}) \ldots \ldots \ldots \ldots \ldots \ldots . \ldots 269$

Burton Rodin. Extremal length and removable boundaries of Riemann surfaces....................... 274

Wu-Chung Hsiang. Locally flat nonembeddability of certain parallelizable manifolds....................... 